\title{
Onderwijs over complementaire behandelwijzen in de medische opleiding
}

P.A. van Dijk, E.M.W. Spee, E. van Rijswijk, W. Gorgels

\section{Samenvatting}

Op nationaal en internationaal niveau wordt gepleit voor onderwijs over complementaire behandelwijzen in de medische opleiding. Aan de hand van een systematische inventarisatie wordt een beeld geschetst van de huidige omvang en de inhoud van het onderwijs over complementaire behandelwijzen aan de Nederlandse medische faculteiten. Daarnaast wordt op basis van een literatuuronderzoek een overzicht gegeven van de situatie in het buitenland.

Op zeven van de acht medische faculteiten in Nederland zijn er onderwijsactiviteiten op het gebied van complementaire behandelwijzen. Het onderwijs heeft echter een weinig gestructureerd karakter: het meeste onderwijs wordt gegeven in de vorm van keuzeonderwijs, het aantal participerende studenten is beperkt en het onderwijs heeft weinig consistentie in de tijd.

In de VS en Canada heeft het merendeel van de medische faculteiten complementaire behandelwijzen in het onderwijspakket. In Europa is het aantal faculteiten met onderwijs op dit gebied aanzienlijk lager. Nederland lijkt wat betreft de aandacht voor dit onderwerp meer op de VS en Canada dan op andere Europese landen.

De auteurs concluderen dat onderwijs over complementaire behandelwijzen past binnen de opvattingen over medisch onderwijs in Nederland. Zij pleiten voor een meer gestructureerde aandacht voor onderwijs over complementaire behandelwijzen aan de Nederlandse medische faculteiten. (Dijk PA van, Spee EMW, Rijswijk E van, Gorgels W. Onderwijs over complementaire behandelwijzen in de medische opleiding. Tijdschrift voor Medisch Onderwijs 2008;27(4):191-202.)

\section{Inleiding}

Op nationaal en internationaal niveau wordt gepleit voor onderwijs over complementaire behandelwijzen in de medische opleiding. ${ }^{1-3}$ In Nederland verstaat men onder complementaire behandelwijzen al die vormen van diagnostiek en therapie die niet aan de medische faculteiten of officieel erkende medische opleidingen worden gedoceerd. ${ }^{1}$

Internationaal spreekt men steeds vaker over 'complementary and alternative medicine', afgekort als CAM. In dit artikel is gekozen voor 'complementaire behandel- wijzen'. Complementair, omdat bedoelde behandelingen veelal worden gepresenteerd als aanvullend op de reguliere interventies. De term behandelwijzen verdient de voorkeur boven 'geneeswijzen', omdat niet duidelijk is of betreffende behandelingen ook genezen.

De Wereldgezondheidsorganisatie dringt in haar rapport 'WHO Traditional Medicine Strategy 2002-2005' bij de lidstaten aan op regelgeving en integratie van complementaire behandelwijzen. Wetenschappelijk onderzoek en onderwijs op dit gebied binnen de reguliere medische op- 
Onderwijs over complementaire behandelwijzen | P.A. van Dijk et al.

leidingen wordt van groot belang gevonden. ${ }^{2}$ Het Europees parlement gaat uit van de vrije therapiekeuze voor de patiënt. Zij heeft de Europese Commissie verzocht complementaire behandelwijzen te erkennen en in de opleidingen van artsen aandacht te besteden aan dit onderdeel van de gezondheidszorg. ${ }^{3}$

In ons eigen land kwam de door de overheid ingestelde 'Commissie Alternatieve Geneeswijzen' in haar eindrapport met een achttal aanbevelingen aan de overheid. De meeste daarvan zijn de afgelopen jaren opgevolgd. Eén van de aanbevelingen luidde: "het bevorderen van informatieverstrekking over alternatieve geneeswijzen aan de bestaande universitaire- en paramedische opleidingen." ${ }^{1}$

Onder de Nederlandse bevolking is betrekkelijk veel belangstelling voor complementaire behandelwijzen. Uit het laatste onderzoek van het Centraal Bureau voor de Statistiek (CBS) in 2007 komt naar voren dat ruim $6 \%$ van de Nederlanders jaarlijks een complementair behandelaar bezoekt. ${ }^{4}$ Als we alle bezoeken aan complementair werkende huisartsen meetellen is dit zelfs $10 \% .^{4}$ Patiënten willen betrouwbare informatie over complementaire behandelwijzen. ${ }^{5}$ Bijna driekwart van de bevolking vindt het nodig dat hij/zij met de huisarts kan overleggen over een eventueel bezoek aan de complementair behandelaar. Tweederde vindt het tevens van belang dat de huisarts erachter staat als men een complementair behandelaar bezoekt. ${ }^{6}$ Een meerderheid van de patiënten verwacht van hun huisarts en specialist dat hij iets van complementaire behandelwijzen afweet en vragen op dat gebied kan beantwoorden. ${ }^{7-8}$ Uit het recente TNS NIPO-onderzoek "De huisarts-patiënt relatie anno 2006", dat in opdracht van het Nederlands Huisartsen Genootschap (NHG) werd uitgevoerd, blijkt dat bijna alle patiënten vinden dat de huisarts een regierol moet heb- ben in de zorg. Ruim $98 \%$ van de Nederlanders wil dat de huisarts op de hoogte blijft van wat er gebeurt rond hun behandeling. ${ }^{9}$ Het is onwaarschijnlijk dat dit standpunt niet de complementaire behandelwijzen omvat.

Huisartsen menen dat ze een taak hebben in het adviseren van patiënten over complementaire behandelwijzen: driekwart van hen vindt dat de huisarts iets van de belangrijkste complementaire behandelwijzen moet afweten en dat de patiënt met vragen daarover bij de huisarts terecht moet kunnen. ${ }^{5}{ }^{10}$ Uit het eerder genoemde TNS NIPO-onderzoek blijkt ook dat de huisarts de regierol in de zorg ambieert.

Wanneer men van mening is dat de (huis)arts de patiënt moet kunnen adviseren over complementaire behandelwijzen, heeft dit als consequentie dat hieraan aandacht moet worden besteed in het medisch onderwijs. Medische studenten zelf staan hier positief tegenover zo blijkt uit onderzoek in de VS, Canada en Engeland. ${ }^{11-13}$ In de VS pleiten belangrijke medische beroepsorganisaties en universiteiten, zoals de 'American Medical Association' en het 'Consortium of Academic Health Centers for Integrative Medicin' voor onderwijs over complementaire behandelwijzen. ${ }^{5}$ De 'British Medical Association' heeft de universiteiten aanbevolen om medisch studenten tenminste te onderwijzen in de basisgedachte van complementaire behandelwijzen. ${ }^{14}$

In dit artikel willen wij een beeld schetsen van de omvang en inhoud van onderwijs over complementaire behandelwijzen aan de Nederlandse medische faculteiten. Daarnaast wordt de Nederlandse situatie vergeleken met die in het buitenland.

\section{Methode}

De gegevens van dit artikel zijn gebaseerd op een systematische inventarisatie van het onderwijsaanbod aan de Nederlandse 
medische faculteiten op het gebied van de complementaire behandelwijzen en op een literatuuronderzoek naar het onderwijs in het buitenland.

\section{Systematische inventarisatie van de situatie in Nederland}

De onderwijscoördinatoren van alle acht medische faculteiten zijn per e-mail benaderd. De namen van de coördinatoren werden verkregen via de facultaire internetsites of via contactpersonen. Bij geen respons werden, via e-mail, reminders gestuurd. De coördinatoren werden ondervraagd over de volgende onderwerpen: naam van het onderwijsblok over complementaire behandelwijzen, soort onderwijs (kern- of keuze-), doelen en onderwerpen, hoeveelheid studenten, positionering in opleiding, onderwijsvormen en duur en frequentie van het onderwijs. De verwerkte antwoorden werden vervolgens ter controle weer voorgelegd aan de respectievelijke onderwijscoördinatoren.

\section{Literatuuronderzoek naar het onderwijs in het buitenland}

Een overzicht van de situatie in het buitenland is verkregen door literatuuronderzoek. Er werd met name gebruik gemaakt van de zoekmachine Pubmed. In Pubmed werd gezocht met de MESH- termen 'complementary medicine' AND 'medical education'. Hiermee vonden wij 265 artikelen. Uit deze artikelen is door middel van een screening van de abstracts een selectie gemaakt. Criteria voor inclusie waren: 1) beschrijving van het onderwijs in de opleiding tot basisarts en 2) systematische beschrijving van aard en omvang van het onderwijs over complementaire behandelwijzen. Daarnaast is gebruik gemaakt van de referenties van de al gevonden artikelen. Uiteindelijk zijn via Pubmed 54 bruikbare artikelen gevonden. Er werd gezocht tot de publicatiedatum december 2006 .
De internet-zoekmachines Google, Google scholar en Scirus zijn gebruikt om websites te vinden van medische studentenverenigingen. In deze drie zoekmachines zijn verschillende combinaties gebruikt van de zoektermen 'association', 'medical', 'student', 'complementary', 'school', 'education' and 'medicine'.

\section{Resultaten}

\section{Medische faculteiten in Nederland}

Aan alle acht medische faculteiten is gevraagd of er onderwijsactiviteiten zijn op het gebied van complementaire behandelwijzen. Er werden in totaal 14 personen die een centrale rol spelen in het geneeskundeonderwijs aangeschreven/gemaild. Met alle acht faculteiten is daadwerkelijk contact gelegd. De resultaten zijn weergegeven in tabel 1.

Van de acht Nederlandse medische faculteiten werd er in 2006 op zeven faculteiten onderwijs gegeven over complementaire behandelwijzen. Alleen op de medische faculteit van Rotterdam zijn geen activiteiten op dit gebied. In totaal zijn er 11 vakken gevonden waarin complementaire behandelwijzen een substantieel onderdeel vormen van het aangeboden onderwijs. Drie van deze vakken maken deel uit van het kernonderwijs. De overige acht vakken behoren tot het keuzeonderwijs.

De doelen van het onderwijs zijn opvallend gelijkluidend voor de verschillende vakken. Kennismaken met complementaire behandelwijzen staat centraal in zeven van de 11 vakken. Het belichten van de relatie tussen regulier en complementair wordt binnen vier vakken als doel aangegeven. De onderwerpen die aan bod komen binnen de verschillende onderwijsprogramma's zijn te verdelen in vijf categorieën: 
- Denkwijzen en praktijk van complementaire behandelwijzen

- Relatie tussen regulier en complementair

- Evidence based medicine en complementaire behandelwijzen

- Arts-patiënt relatie

- Maatschappelijke aspecten van complementaire behandelwijzen.

Complementaire behandelwijzen die het meest besproken worden zijn in frequentie van voorkomen: homeopathie, acupunctuur, antroposofische geneeskunde, natuurgeneeskunde, manuele therapie, paranormale geneeswijze en fytotherapie. Onderwijs over complementaire behandelwijzen wordt gegeven in het tweede tot en met het vijfde jaar. Bij alle vakken wordt gebruik gemaakt van werk- en/of hoorcolleges. De hoeveelheid onderwijstijd die aan complementaire behandelwijzen wordt besteedt varieert van één college tot vier weken full time.

Het aantal deelnemende studenten is zeer variabel. Voor sommige keuzevakken zijn er slechts vier studenten, voor een aantal vakken uit het kerncurriculum gaat het over hele jaargroepen.

Bij één keuzevak komt het initiatief voor het onderwijs van de Nederlandse Vereniging voor Klassieke Homeopathie (lectoraat VU Amsterdam). Drie medische faculteiten hebben expliciet zelf het initiatief voor onderwijs over complementaire behandelwijzen genomen. Van de overige faculteiten hebben wij geen informatie. De duur en frequentie van het onderwijs loopt voor de verschillende faculteiten sterk uiteen. Vijf van de tien vakken in complementaire behandelwijzen zijn gestart in 2005 en 2006.

\section{Medische faculteiten in het buitenland}

De resultaten van de literatuurstudie naar complementaire behandelwijzen op medische faculteiten in het buitenland zijn verwerkt in tabel 2. Uit deze studie komt naar voren dat er in de VS veel medische faculteiten zijn die complementaire behandelwijzen in het onderwijs hebben opgenomen. Uit een in 1998 uitgevoerd onderzoek bleek dat 75 van de 117 onderzochte medische faculteiten $(64 \%)$ in de VS complementaire behandelwijzen in het onderwijspakket hebben. ${ }^{15-16}$ In Canada gaven in 1999 zelfs 13 van de 16 faculteiten (81\%) een vak met complementaire behandelwijzen. ${ }^{17}$ In Japan ligt het aantal vakken met complementaire behandelwijzen aanzienlijk lager. Er zijn daar 16 van de 80 faculteiten $(20 \%)$ die onderwijs geven op dit gebied. ${ }^{18}$ Over de rest van Azië, Australië en Zuid-Amerika zijn geen gegevens beschikbaar. In de Europese Unie wordt op ruim een derde van de onderzochte medische faculteiten onderwijs gegeven over complementaire behandelwijzen. ${ }^{19-20}$

De doelen die men stelt bij het aanbieden van onderwijs over complementaire behandelwijzen in het buitenland komen redelijk overeen. Zowel in Noord-Amerika als in Europa is het kennismaken met complementaire behandelwijzen het meest genoemde doel. ${ }^{15}{ }^{21-30}$ Een aantal medische faculteiten stelt zich ten doel de student te leren de principes van evidence based medicine te gebruiken om complementaire behandelwijzen te evalueren. ${ }^{22}{ }^{31-33}$ De Texas University gebruikt complementaire behandelwijzen om studenten te leren literatuur research te doen. ${ }^{31-32}$ Andere genoemde doelen zijn: inzicht krijgen in de relatie complementair - regulier ${ }^{33-34} \mathrm{en}$ het met respect leren kijken naar andere (sub)culturen. ${ }^{35}$

Wat betreft de onderwerpen ligt het accent in de VS vooral op de context van de 


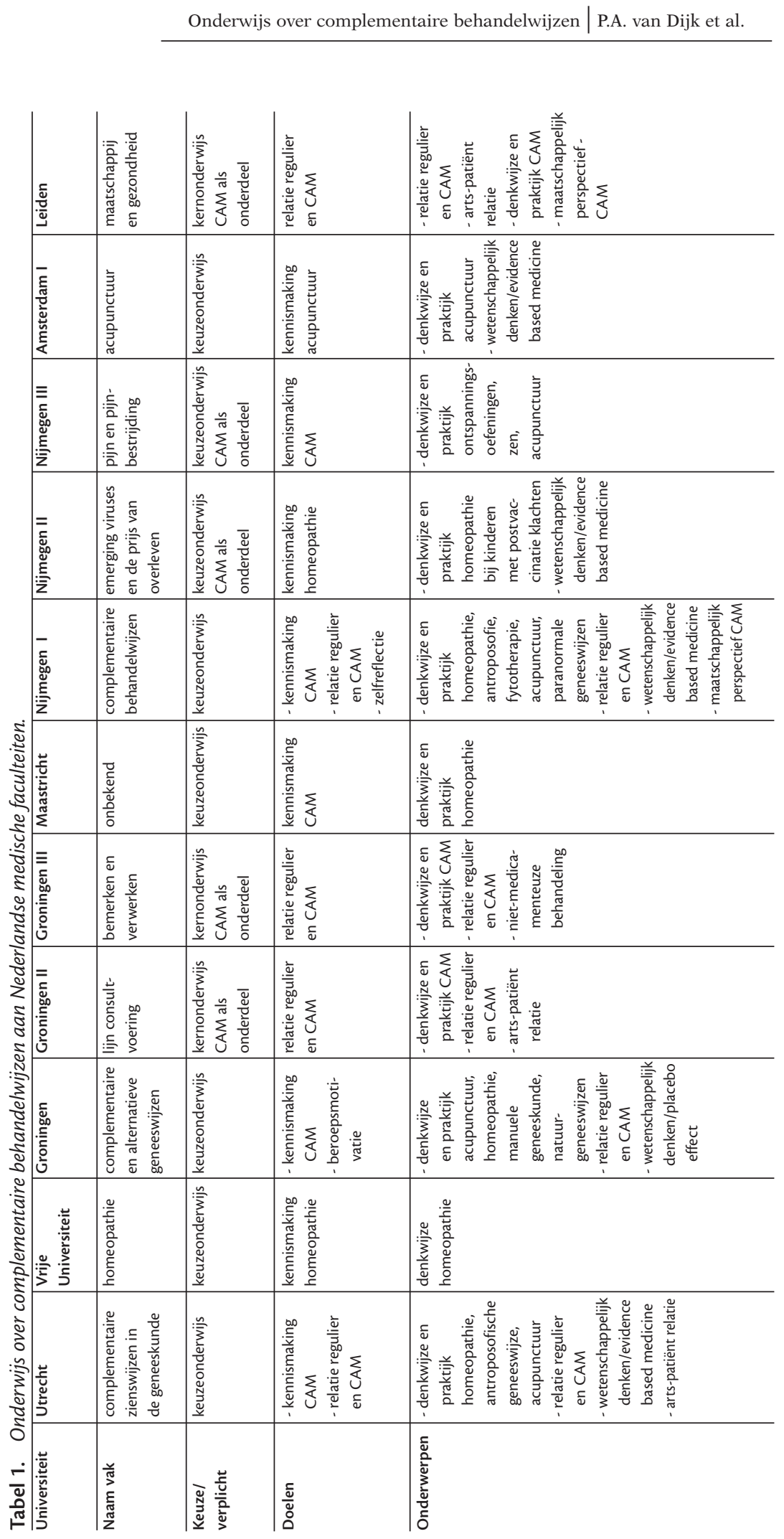




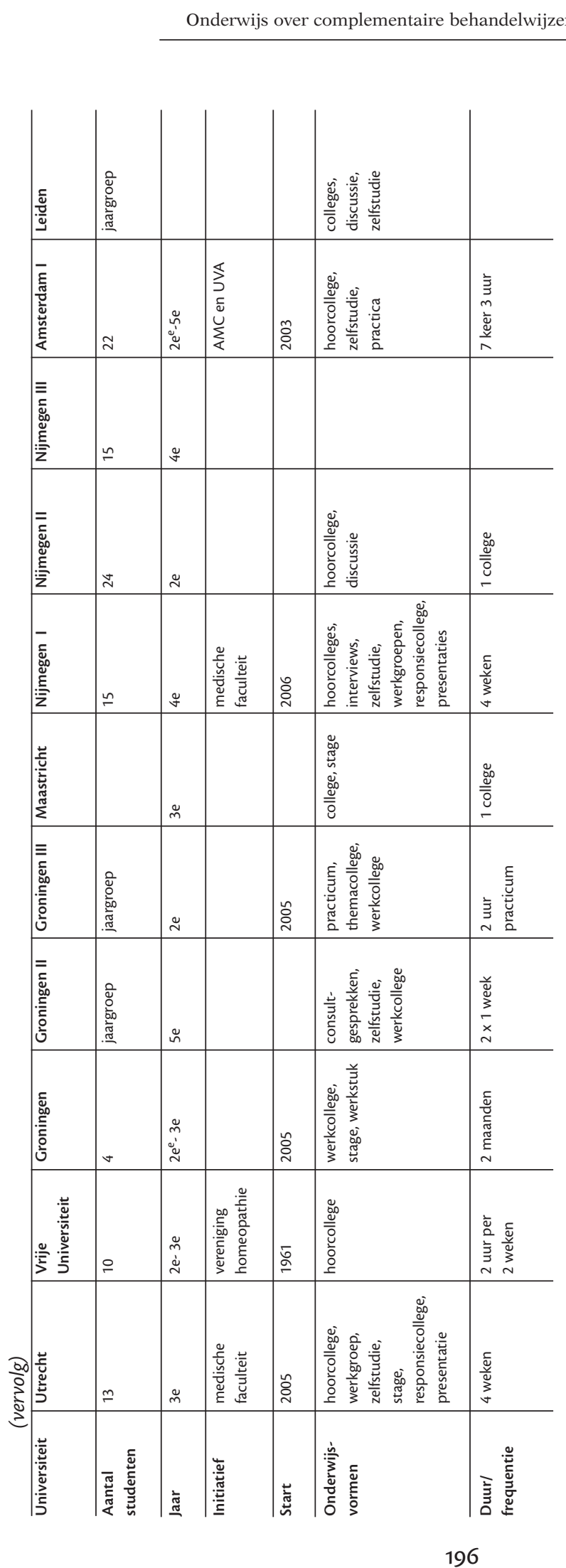


complementaire behandelwijzen. Aan bod komen in dit kader ondermeer: andere culturen $^{35}$, spiritualiteit ${ }^{35}$, epidemiologie ${ }^{31-}$ ${ }^{32}$, evidence based medicine ${ }^{36}$ en placebobehandeling. ${ }^{24}$ Behandelwijzen die tegen deze achtergronden worden besproken zijn Chinese geneeskunde, homeopathie, voedingssupplementen/vitaminen, yoga en relaxatietechnieken. Relatief veel aandacht is er voor humanistische geneeskunde. ${ }^{33}$

De curricula in Europa beperken hun onderwerpen veelal tot het ter sprake brengen van een aantal behandelwijzen (acupunctuur, homeopathie, chiropractie, natuurgeneeskunde) of plaatsen complementaire behandelwijzen in het kader van de geschiedenis van de geneeskunde. Op verschillende Engelse faculteiten is de relatie complementaire behandelwijzen en evidence based medicine het onderwijsthema. 22 26-28

In de VS komen complementaire behandelwijzen aan bod in de eerste vier jaren van het curriculum, waarvan het merendeel in de eerste twee jaren. Op de Engelse faculteiten wordt het onderwijs gegeven in het eerste, tweede en derde jaar.

Duur en frequentie van het onderwijs in het buitenland variëren sterk. Het aantal deelnemende studenten is bij de verplichte vakken groot (honderden studenten) en bij de keuzevakken klein (zes tot 30 studenten).

\section{Discussie}

\section{Medische faculteiten in Nederland}

Op dit moment zijn er op zeven van de acht medische faculteiten onderwijsactiviteiten op het gebied van complementaire behandelwijzen. Op een aantal faculteiten gaat het om meerdere vakken.

De doelen die men in Nederland stelt aan onderwijs over complementaire behandelwijzen komen opvallend overeen.
Bij de verplichte vakken is het onderwijs vooral gericht op de relatie tussen regulier en complementair. Bij de keuzevakken komt dit ook aan de orde maar heeft men tevens als doel studenten kennis te laten maken met een aantal complementaire behandelwijzen.

Ook wat betreft de onderwerpen die op de verschillende medische faculteiten aan bod komen is er veel overeenkomst. Opvattingen en praktijk van complementaire behandelwijzen, de relatie regulier - complementair en het spanningsveld tussen complementaire behandelwijzen en evidence based medicine zijn de belangrijkste thema's. Vaak staan de volgende zeven complementaire behandelwijzen centraal: homeopathie, acupunctuur, antroposofische geneeskunde, paranormale geneeswijze, natuurgeneeskunde, manuele therapie en fytotherapie. Dit zijn ook de behandelwijzen die in Nederland de grootste consumptie laten zien. ${ }^{37}$

Dit artikel geeft een overzicht van het onderwijs over complementaire behandelwijzen aan medische faculteiten in Nederland. Door uitgebreide contacten met de verschillende medische faculteiten kan worden aangenomen dat dit overzicht volledig is. Belangrijk is wel op te merken dat het een momentopname betreft. Het feit dat de helft van de huidige vakken gestart is in 2005 en 2006 geeft de korte geschiedenis aan en/of het gebrek aan continuïteit.

\section{Medische faculteiten in het buitenland}

Op basis van het literatuuronderzoek hebben we een goed algemeen beeld kunnen krijgen van het aangeboden onderwijs in het buitenland. Het beeld zal echter niet compleet zijn omdat niet alle inventarisaties gepubliceerd worden in peer reviewed tijdschriften. In veel landen is bovendien nooit onderzoek gedaan naar complementaire behandelwijzen in medische onderwijsprogramma's. De terminologie en 


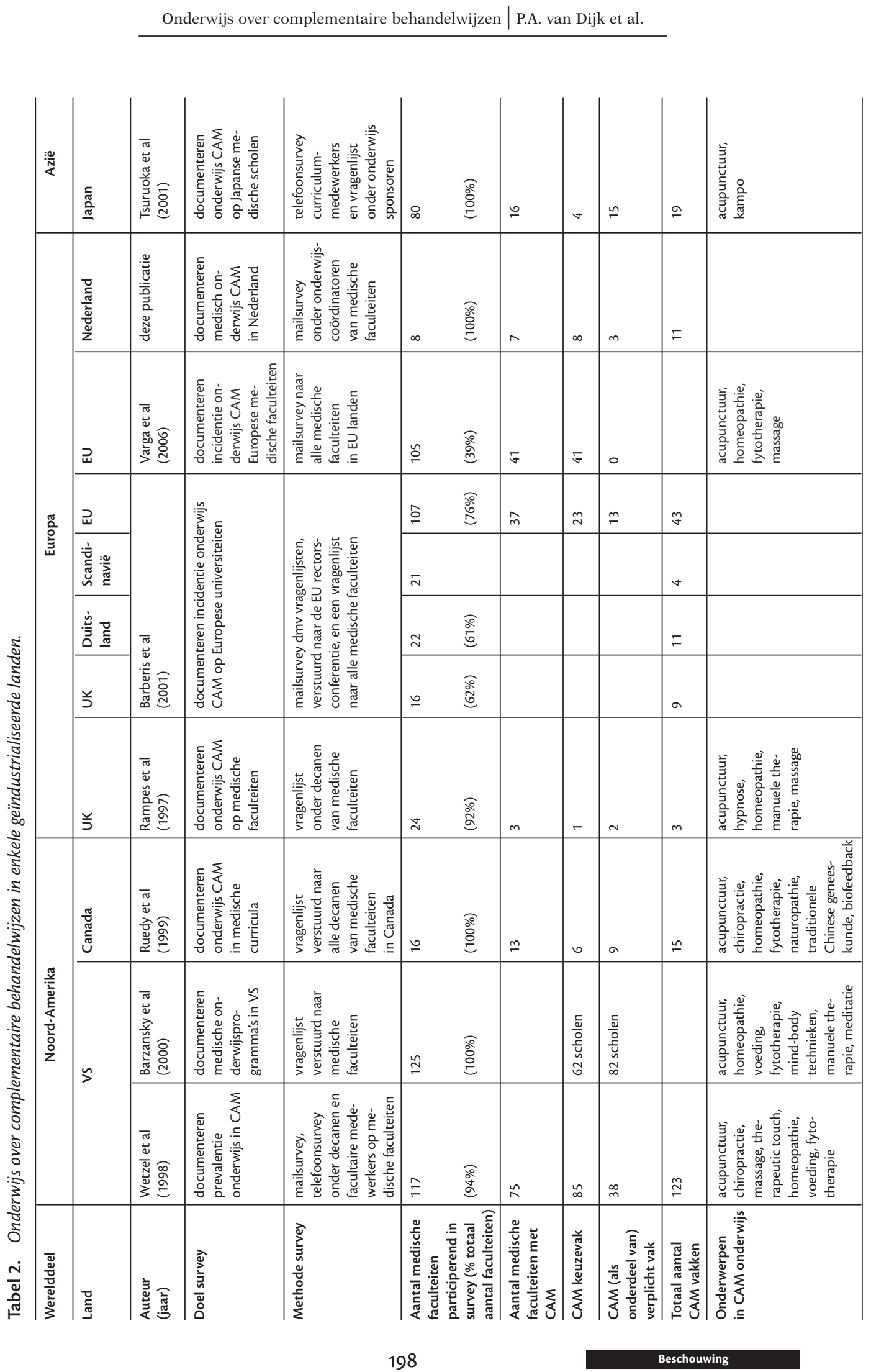


definities zijn niet eenduidig. Er wordt in de literatuur gesproken over complementaire geneeswijzen, complementaire behandelwijzen, alternatieve geneeswijzen, holistische geneeskunde, onorthodoxe geneeswijzen, integrale geneeskunde, onconventionele geneeswijzen. In de Engelstalige publicaties is de term CAM (Complementary and Alternative Medicine) redelijk universeel. Rekening houdend met de beperkingen van deze literatuurstudie is dit, zover bekend, de eerste keer dat een vergelijkend onderzoek is gedaan naar het voorkomen en de presentatie van complementaire behandelwijzen op medische faculteiten in het buitenland. Ook voor de Nederlandse situatie werd nooit eerder een inventarisatie gemaakt.

Het aantal medische faculteiten in het buitenland dat complementaire behandelwijzen in het curriculum heeft opgenomen wisselt sterk per land. In de VS en Canada heeft het merendeel van de medische faculteiten complementaire behandelwijzen in het onderwijspakket. ${ }^{16-17}$ In Europa is het aantal faculteiten met complementaire behandelwijzen aanzienlijk lager. ${ }^{19}$

\section{Nederland versus het buitenland}

In de vergelijking van de gegevens van Nederland met het buitenland dient opgemerkt te worden dat de gegevens uit het buitenland van eerdere datum zijn dan de Nederlandse gegevens. In Nederland geven zeven van de acht medische faculteiten onderwijs over complementaire behandelwijzen. Dat is veel in vergelijking met de andere Europese landen die onderzocht zijn in deze studie. Nederland lijkt wat betreft het aanbod van complementaire behandelwijzen in het medisch onderwijs meer op de VS en Canada waar ook een ruime meerderheid van de faculteiten onderwijs over complementaire behandelwijzen aanbiedt.
De doelen die men zich in Nederland stelt bij het geven van onderwijs op dit gebied zijn niet veel anders dan die in het buitenland. In Nederland en in de buitenlandse situatie is het hoofddoel een kennismaking met de opvattingen van de belangrijkste complementaire behandelwijzen en een beeldvorming over de verhouding tussen de reguliere en de complementaire gezichtspunten. In de VS is er mogelijk meer aandacht voor cultuur en achtergronden van de behandelwijzen.

Wat betreft de aangeboden onderwerpen valt op dat er in de Nederlandse situatie een grote overeenkomst is tussen de verschillende faculteiten. Dit kan niet gezegd worden van de medische faculteiten in de VS en Canada. Hier komen uiteenlopende onderwerpen aan bod. In de andere Europese landen beperkt men zich tot het bespreken van de opvattingen van een aantal complementaire behandelwijzen.

De behandelwijzen die aandacht krijgen in Nederland zijn in grote lijnen ook de meest besproken therapieën in het buitenland. Een uitzondering is de antroposofische geneeskunde. Deze behandelwijze treft men voornamelijk aan in Nederland en Zwitserland. In Duitsland is er relatief veel aandacht voor natuurgeneeskunde. In Engelstalige landen is er een opvallende plaats voor chiropractie.

Het onderwijs in Nederland wordt gegeven in verschillende studiejaren. Het varieert voor de verschillende programma's van het tweede tot het vijfde jaar. In de VS en Canada wordt het onderwijs vooral in de eerste twee jaren gegeven, maar ook in het derde en vierde jaar zijn de complementaire behandelwijzen in het programma opgenomen. Over de Europese landen buiten Nederland zijn er te weinig gegevens.

Onderwijsvormen die voor dit onderwijs gekozen worden zijn in het buitenland niet 
Onderwijs over complementaire behandelwijzen | P.A. van Dijk et al.

anders dan in Nederland. Het gaat om hoorcolleges, responsiecolleges, werkgroepen, stages en groepsdiscussies. In Nederland betreft het bij 73\% van de vakken keuzeonderwijs. In de door ons onderzochte buitenlandse faculteiten was dat $57 \%$.

\section{Conclusie}

Op bijna alle medische faculteiten in $\mathrm{Ne}$ derland wordt onderwijs over complementaire behandelwijzen gegeven. Het onderwijs heeft echter een weinig structureel karakter: het meeste onderwijs wordt gegeven in de vorm van keuzeonderwijs, het aantal participerende studenten is beperkt en het onderwijs kent weinig consistentie in de tijd. Andere Europese landen en de VS geven eenzelfde beeld.

In het Raamplan van de artsenopleiding staat dat een arts open moet staan voor de behoefte en verwachtingen van de patiënt en diens normen en waarden. Een arts dient zich in te zetten en zich mede verantwoordelijk te voelen voor het lichamelijke, geestelijke en sociale welzijn van mensen en voor alle vormen van gezondheidszorg. Onderwijs over complementaire behandelwijzen past in die visie. Er lijkt derhalve binnen de basisopvattingen van het medisch curriculum ruimte voor onderwijs over complementaire behandelwijzen. Dit gevoegd bij het feit dat overheden, patiënten, huisartsen en medisch studenten in meerderheid van mening zijn dat dit onderwijs gewenst is, lijkt het relevant om op medische faculteiten in Nederland meer gestructureerd aandacht te besteden aan de plaats en de inhoud van onderwijs over complementaire behandelwijzen.

\section{Literatuur}

1. Commissie Alternatieve Geneeswijzen. Leidschendam: Ministerie van volksgezondheid en milieuhygiëne; 1981. [Committee on Alternative Medicine. Leidschendam: Ministry of Health and the Environment; 1981].

2. WHO Traditional Medicine Strategy 2002-2005. Geneva: Traditional Medicine Team WHO; 2002.

3. Lannoye P. Verslag over de status van de niet-conventionele geneeskunde. Brussel: Commissie in opdracht van het Europees parlement; 1997. [Report on the position of non-conventional medicine. Brussels: Committee set up by the European Parliament; 1997].

4. Centraal Bureau voor de Statistiek. Gebruik medische voorzieningen. Voorburg/Heerlen: Statline databank; 2007. [Statistics Netherlands. Use of medical facilities. Voorburg/Heerlen: Statline databank; 2007].

5. Frenkel M, Arye EB. The growing need to teach about complementary medicine. Acad Med. 2001;76:251-4.

6. Bos JM. Het Winterswijkse samenwerkingsexperiment. Tijdschr Int Geneeskd 1996;5:124-8. [The Winterswijk Collaborative Experiment. Dutch Journal of Internal Medicine 1996;5:124-8].

7. Stam C. Summery of results of a representive public survey. Amsterdam: Bureau Interview; 1998.

8. Vlieger AM, Putte EM van, Hoeksma H. Het gebruik van complementaire en alternatieve geneeswijzen door kinderen op een polikliniek. Ned Tijdschr Geneeskd 2006;150(11):625-30. [The use of complementary and alternative medical therapies in a paediatric outpatient clinic. Dutch Medical Journal 2006;150(11):625-30].

9. TNS NIPO. De huisarts-patiëntrelatie anno 2006. Amsterdam: Rapport in opdracht van het NHG; 2006. [The doctor- patient relationship in 2006. Amsterdam: Report commissioned by the Dutch College of General Practitioners; 2006].

10. Visser GJ, Peters L. Alternative medicine and general practitioners in the Netherlands. Fam Pract 1990;7:227-32.

11. Greenfield SM, Brown R, Dawlatly SL, Reynolds JA, Roberts S, Dawlatly RJ. Gender differences among medical students in attitudes to learning about complementary and alternative medicine. Complement Ther Med 2005;14:207-12.

12. Duggan K, Verhoef MJ, Hilsden RJ. First year medical students and complementary medicin. Ann Coll Physician Surg Can 1999;32:157-60.

13. Jonas W. Alternative medicine and the conventional practitioner. JAMA 1998;279 (9):708-10.

14. Morgan D, Glanville H, Mars S, Nathason V. Education and training in complementary medicine. A postal survey of UK universities. Compl Ther Med 1998; 6:64-70. 
Onderwijs over complementaire behandelwijzen $\mid$ P.A. van Dijk et al.

15. Wetzel MS, Kaptchuk TJ, Haramati A, Eisenberg DM. Complementary and alternative medical therapies: implications for medical education. Ann Intern Med 2003;183:191-7.

16. Barzansky B, Jonas HS, Etzel SI. Educational programs in US medical schools, 1999-2000. JAMA 2000; 284:1114-20.

17. Ruedy J, Kaufman DM, MacLeod H. Alternative and complementary medicine in Canadian medical schools: a survey. JAMC 1999;160:816-7.

18. Tsuruoka K, Tsuruoka Y. Kajii E. Complementary medicine education in Japanese medical schools: a survey. Complement Ther Med 2001;9:28-33.

19. Barberis L, De Toni E, Schiavone M, Zicca A, Ghio R. Unconventional medicine teaching at the universities of the European Union. J Alt Complement Med.2001;7:337-43.

20. Varga O, Márton S, Molnar P. Status of complementary and alternative medicine in European Medical Schools. Fosch Komplem Med 2006;13:41-5.

21. Berman BM. Complementary medicine and medical education: teaching complementary medicine offers a way of making teaching more holistic. BMJ 2001;322:121-2.

22. Maizes V, Schneider C, Bell I, Weil A. Integrative medical education: development and implementation of a comprehensive curriculum at the University of Arizona. Acad Med 2002;77:851-60.

23. Haramati A, Lumpkin MD. Integrating complementary and alternative medicine into conventional medical education: role of basic science. Arch Intern Med 2001;161:1679.

24. Jeffries WB. A fourth year elective course in alternative medicine. Acad Med 2001;76:525-6.

25. Magwood B, cariso O, Hennen B. The medical humanities program at the university of Manitoba, Winnipeg, Manitoba, Canada. Acad Med 2003;78:1015-9

26. Owen D, Lewith GT. Complementary and alternative medicine (CAM) in the undergraduate medical curriculum: the Southampton experience. Med Educ 2001;35:73-7.

27. Owen DK, Lewith G, Stephens CR. Can doctors respond to patients' increasing interest in complementary and alternative medicine? BMJ 2001;322:154-7.

28. Lewith GT, Owen D: Complementary medicine: the Southampton undergraduate experience. Complement Ther Med. 2000;8:202-6.

29. Bryden H. Commentary: Special study modules and complementary and alternative medicine the Glasgow experience. BMJ 2001;322:157-8.

30. Kiessling C, Müller T, Becker-Witt C, Begenau J, Prinz V, Schleiermacher S. A medical humanities special study module on priciples of medical theory and practice at the Charité, Humboldt University, Berlin, Germany. Acad Med 2003;78:1031-35.
31. Forjuoh SN, Rascoe TG, Symm B, Edwards JC. Teaching medical students complementary and alternative medicine using evidence-based principles. J Alt Complement Med 2003;9: 429-39.

32. Sierpina VS, Philips B. Need for scholarly, objective inquiry into alternative therapies. Acad Med 2001;76:863-4.

33. Greenfield SM, Wearn AM, Hunton M, Innes MA. Considering the alternatives: a special study module in complementary therapy. Complement Ther Med 2000; 8:15-20.

34. Hui KH, Zylowska L, Hui EK, Liang Yu J, Jia Li $\mathrm{J}$. Introducing integrative East-West medicine to medical students and residents. J. Alt Complement Med 2002; 8:507-15.

35. Hull SK, DiLalla LF, Dorsey JK. Student attitudes toward wellness, empathy, and spirituality in the curriculum. Acad Med 2001;76:520.

36. Sampson $\mathrm{W}$. The need for educational reform in teaching about alternative therapies. Acad Med 2001;76:248-50.

37. Dijk PA van. Geneeswijzen in Nederland (negende druk). Deventer: Uitgeverij Ankh Hermes: 2003. Medical therapies in the Netherlands. Deventer: Ankh Hermes Publishers; 2003].

De auteurs:

Drs. P.A.van Dijk (Paul) is huisarts te Zaltbommel. Mw. drs E.M.W.Spee (Erica) is zesdejaars medisch student Nijmegen.

Dr. E.van Rijswijk (Eric) is huisarts en senior onderzoeker afdeling huisartsgeneeskunde, UMC St Radboud Nijmegen.

Drs. W.J.M.J.Gorgels (Wim) is huisarts, afdeling huisartsgeneeskunde, UMC St Radboud Nijmegen.

Correspondentieadres:

Paul van Dijk, Ruiterstraat 10, 5301ED Zaltbommel. Email:paul.vandijk@zonnet.nl

Belangenconflict: geen gemeld

Financiële ondersteuning: geen gemeld 
Onderwijs over complementaire behandelwijzen | P.A. van Dijk et al.

\section{Summary}

The inclusion of instruction in complementary and alternative medicine (CAM) in medical education is being advocated both nationally and internationally. We present an overview of the scope and content of educational activities concerning complementary and alternative medicine in the Dutch faculties of medicine and the results of a literature search concerning the situation outside the Netherlands. Of the total of eight Dutch faculties of medicine, seven offer alternative medicine instruction. These educational activities are not well integrated into the curriculum. Elective courses predominate, participation is limited and activities show little continuity over time. In the USA and Canada most medical schools offer instruction in complementary medicine. The number of European medical schools offering this type of education is considerably lower. The situation in the Netherlands concerning medical education in complementary medicine bears a stronger resemblance to the situation in the USA and Canada than to that in European countries. Education in complementary and medical education appears to be in line with the current objectives of medical education in the Netherlands. The authors advocate efforts to make complementary and alternative medicine a structural component of medical education in the Netherlands. (Dijk PA van, Spee EMW, Rijswijk E van, Gorgels W. The position of complementary and alternative medicine in undergraduate medical education. Dutch Journal of Medical Education 2008;27(4):191-202.) 